\title{
PARASITIC PERIFOLLICULAR DERMATITIS IN THE EGYPTIAN LESSER BLIND MOLE RAT (Spalax leucodon egyptiacus)
}

\author{
Omar A. S. Tamam* \\ Department of Natural Resources, Environmental Studies \& Research Institute \\ University of Sadat City, Egypt
}

\begin{abstract}
A field study of outdoor cultivated habitats was conducted in the northern part of the Western Desert in Egypt (Al Dabaa Marsa Matroh Governorate) between March 2010 and August 2013. Samples were collected from skin lesions occurring on the Egyptian lesser blind mole rat (Spalax leucodon Egyptiacus). Gross examination of the lesions showed alopecia and grey, circumscribed nodules, average size $2-5 \mathrm{~mm}$, in the hair-free thigh regions of the animals, varying from three to ten in number. Skin scrapings revealed numerous Lynxacarus egyptiacus, as well as other ectoparasites including Polyplax serrata and gamasid mites. Histopathological examination of the skin lesions showed features of demodetic perifollicular inflammation with aggregations of eggs in the dermis and in the keratin layer. Destroyed hair follicles were associated with fibroblastic proliferation and lymphocytic infiltration. Invasion with Polyplax serrata and gamasid mites resulted in keratinolysis, itching, and slight haemorrhage.This study is the first study to report on mixed lice infestations, and their associated histopathological changes, occurring in the Egyptian lesser blind mole rat. Since the population of this species is in decline, data relating to pathologies that occur in the Egyptian mole rat are of significance.
\end{abstract}

Key words: Egyptian lesser blind mole rat, Spalax leucodon; Lynxacarus egyptiacus, Polyplax serrata, perifollicular dermatitis

\section{INTRODUCTION}

Ectoparasites in moles can invade the skin and cause alopecia and pruritis (Tamam and Omar, 2009). We previously identified larval, nymphal, and adult male mites in the Egyptian lesser blind mole rat and named them Lynxacarus egyptiacus, after their host (Spalax leucodon Egyptiacus) (Tamam and Omar, 2009). The most prominent clinical signs seen in these seven mole rats were alopecia, intense gingivitis, and periodontitis, with notable swollen, ulcerating, and bleeding gums. Lynxacarus spp. belong to family Listrophoridae, which mainly infest rodents, but Leporacarus gibbus can also cause mange in domesticated rabbits, and Lynxacarus radovskyi affects domesticated and wild cats (Mounsey et al., 2009; Philips, 2000; Lohseet al., 2002). Other ectoparasites that are reported in wild cats, such as Polyplax serrata (Nelson et al., 1979), show a sequence of inflammatory skin changes in mice infested with the louse, which are recognisable as acanthosis, fibrosis, tissue lymphocytosis, and monocytosis, as well as a sustained increase in mast cell numbers accompanied by mast cell degranulation. Some mites that infest the skin, such as Sarcoptidae and Knemidocoptes, can tunnel into the skin and live within these burrows. Others live on the skin surface (non-burrowing mites), fur, and other sites (Hoppmann and Barron, 2007; Jimenez et al., 2010; Kahn et al., 2010; Lohse et al., 2002). Fox et al. (2006) add that Polyplax lice can cause specific lesions in mice that can be identified as small (up to $2 \mathrm{~mm}$ ), whitish, cyst-like dermal nodules on the legs, back, trunk, abdomen, shoulders, and head.

With this background in mind, the objective of this study was to describe the histopathological changes associated with Lynxacarus egyptiacus, Polyplax serrata, and gamasid mites in the Egyptian lesser blind mole rat (Spalax leucodon Egyptiacus).

\section{MATERIALS AND METHODS}

Twenty-five Egyptian lesser blind mole rats were caught between May 2006 and August 2013 by excavating their tunnels, manual capture, and subsequent release after hair collection and biopsy of the skin lesions. All compound microscope and stereoscope. Lynxacarus mites < 500 um were identified by their laterally compressed body and characteristic grasping of the hair shaft between the gnathosoma and palpi. Polyplax serrata were

*Corresponding e-mail address: tamam@nextgenediting.com 


\section{Omar A. S. Tamam}

parasites collected from the bodies of the host were preserved in $70 \%$ ethanol in the field. In the laboratory, individual specimens were dehydrated in a series of graded ethanol solutions $(30 \%, 50 \%, 70 \%, 80 \%, 90 \%, 95 \%$, and $100 \%$ ) before being cleared in a mixed solution of pure ethanol and xylene (Guo et al., 1996; Guo \& Qian, 2001) and being mounted on glass slides. Specimens were then examined thoroughly using both a external parasites collected from the bodies of the host were preserved in $70 \%$ ethanol in the field. In the laboratory, individual specimens were dehydrated in a series of graded ethanol solutions $(30 \%, 50 \%, 70 \%, 80 \%, 90 \%, 95 \%$, and $100 \%$ ) before being cleared in a mixed solution of pure ethanol and xylene (Guo et al., 1996; Guo \& Qian, 2001) and being mounted on glass slides. Specimens were then examined thoroughly using both a

differentiated from $P$. spinulosa by identification of the sternal plate, which is triangular in $P$. serrata and pentagonal in $P$. spinulosa, and the fourth lateral abdominal plate has septa of unequal length in $P$. serrata and equal length in $P$. spinulosa. Other species were identified by microscopy. Skin biopsy samples were collected and fixed in $10 \%$ neutral buffered formalin, dehydrated, embedded in paraffin, sectioned at 5-7um, stained by $\mathrm{H} \& \mathrm{E}$, and examined by light microscopy.

\section{RESULTS}

Moles that exhibited signs of itching and alopecia had well-defined circumscribed grey nodules measuring an average of $2-5 \mathrm{~mm}$ in size in the thigh area free of hairs, varying from one to five in number (Fig. 1A). Skin scrapings from these areas showed flap-like external extensions of elongated Lynxacarus egyptiacusmites encircling the hair with a clasp-like hold around the hair shaft; in total, over 400 Lynxacarus mites were collected from each animal using a toothbrush Fig. 1B) and over 100 Polyplax serrata were collected from each animal using the same method (Fig. 1C). In contrast, gamasid mites were fewer in number $(<20$ specimens from each animal; Fig. 1D).

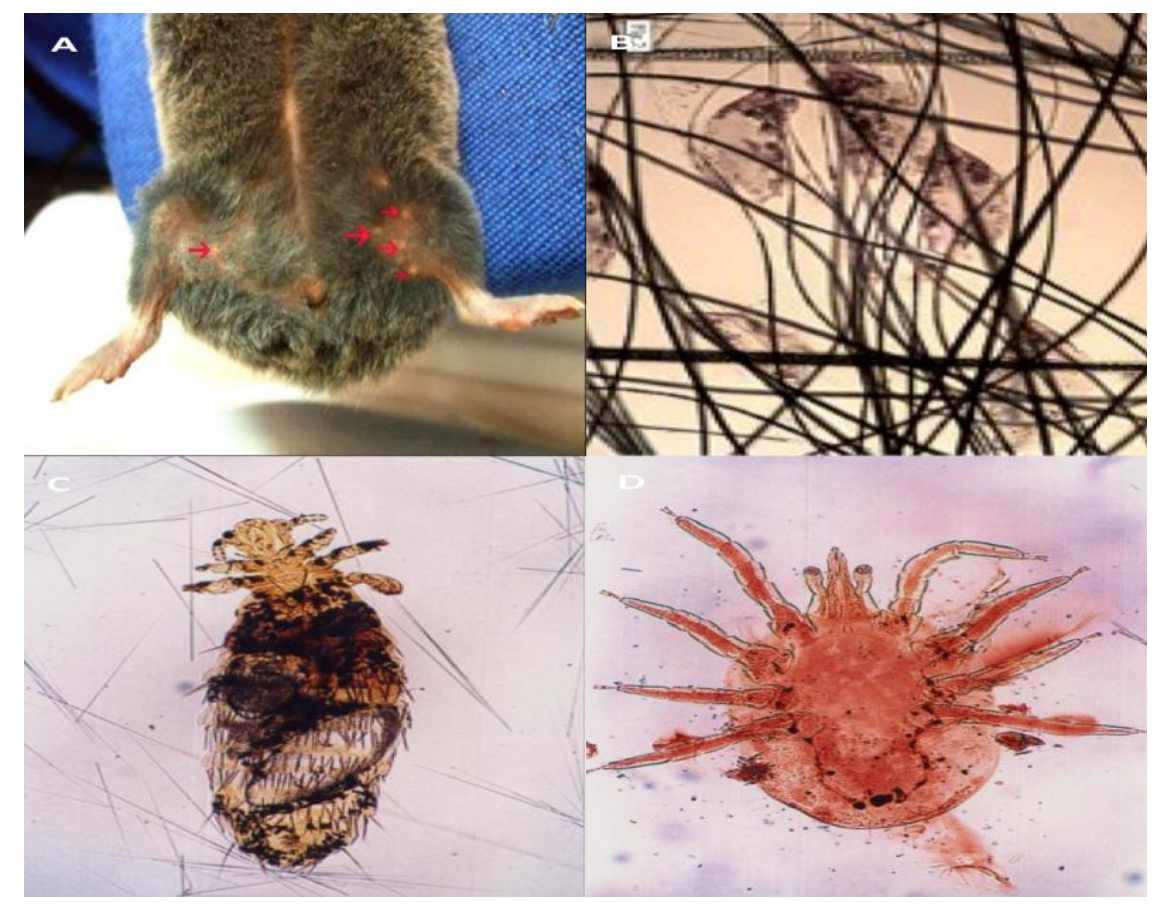

Fig. 1. (A) Circumscribed nodules in areas free from hairs in the thigh region of the Egyptian lesser blind mole rat (Spalax leucodon Egyptiacus). (B) Flap-like external extensions of elongated-shaped Lynxacarus egyptiacus mites encircle the hair with a clasp-like hold around the hair shaft. (C) Polyplax serrata associated with the nodules on the thigh of the Egyptian lesser blind mole rate (Spalax leucodon Egyptiacus). (D) Gamasid mites were recorded in low numbers and no obvious pathological significance. 
Tissue sections revealed the presence of elongated to rounded structures above the epidermis, and collections of these eggs were also found supra-epidermally within and above the keratin layer (Fig. 2A). In these regions where mites were observed above the epidermis, the dermis exhibited a granulomatous reaction (Fig. 2B). Collections of eggs were also found invading the hair follicles in the dermis and encircled by a thin layer of fibrous connective tissue (Fig. 2C), with fibroblasts and lymphocytes surrounding and encircling the eggs in the dermis, forming granulomas (Fig. 2D).

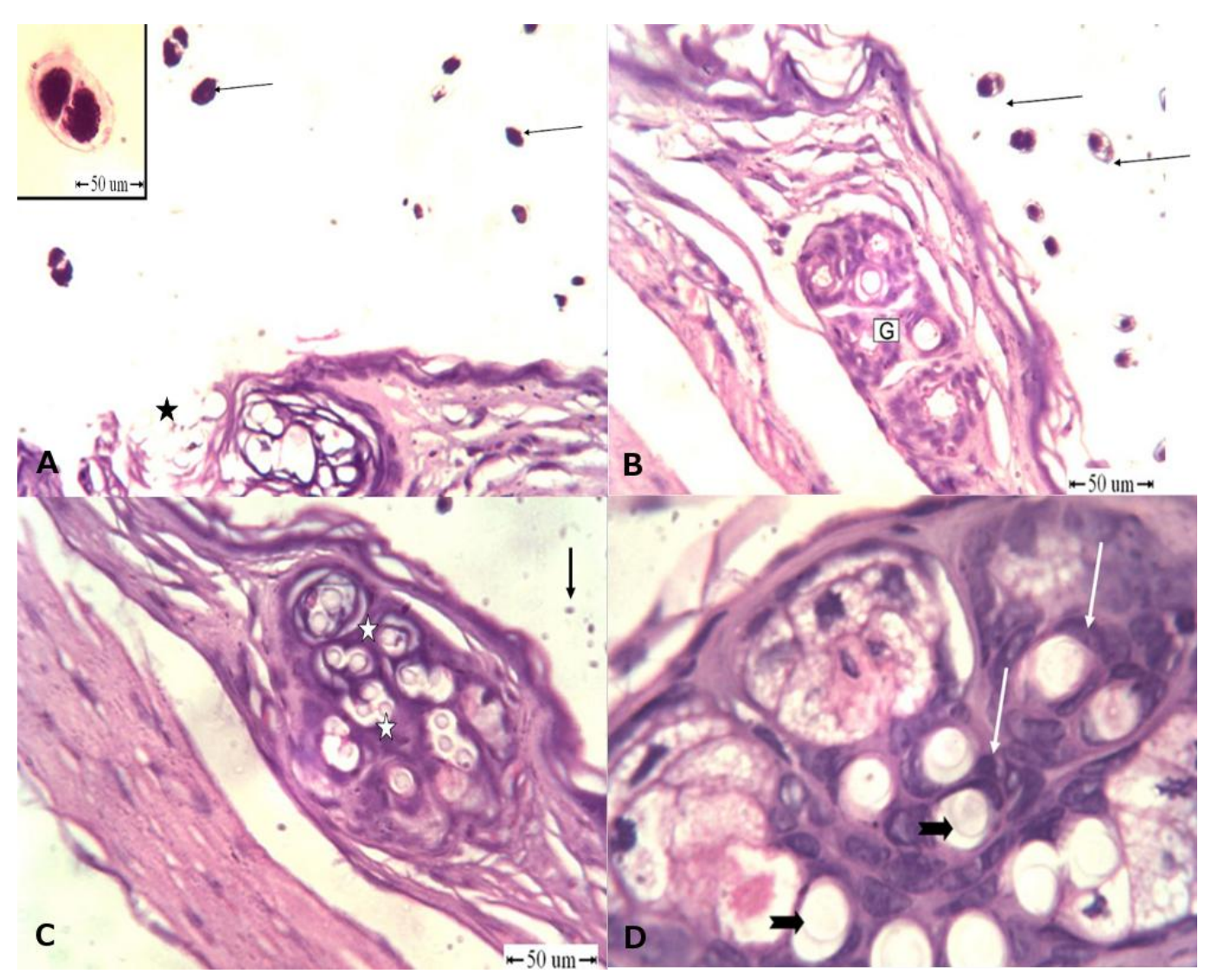

Fig. 2. (A) Several elongated to round structures above the epidermis (approximately 10-15 mm; arrow); collection of rounded eggs (star). The inset shows the elongated mite. H\&E. (B) Several elongated to round structures above the epidermis (arrow). Note the granulomatous reaction in the dermis (G). H\&E. (C) Lynxacarus radovskyi above the epidermis (arrow). Encircled eggs invaded the hair follicles in the dermis (star). H\&E. (D) Fibroblasts (arrow) encircle the eggs in the granulomas.

Sometimes the eggs were arranged in circles or in a crown-like pattern above the hair follicles and surrounded by prominent fibroblasts (Fig. 3A). Fig. 3 shows that fibroblasts and lymphocytes constituted the dermal granulomatous reaction. Remnants of the hair shaft were surrounded by intense fibroblastic proliferation and lymphocytes were also noted (Fig. 3B). Polyplax serrata lice were observed in association with Lynxacarus egyptiacus (Fig. 3C), and were sometimes associated with haemorrhage and keratinolysis where the lice had invaded (Fig. 3D). 


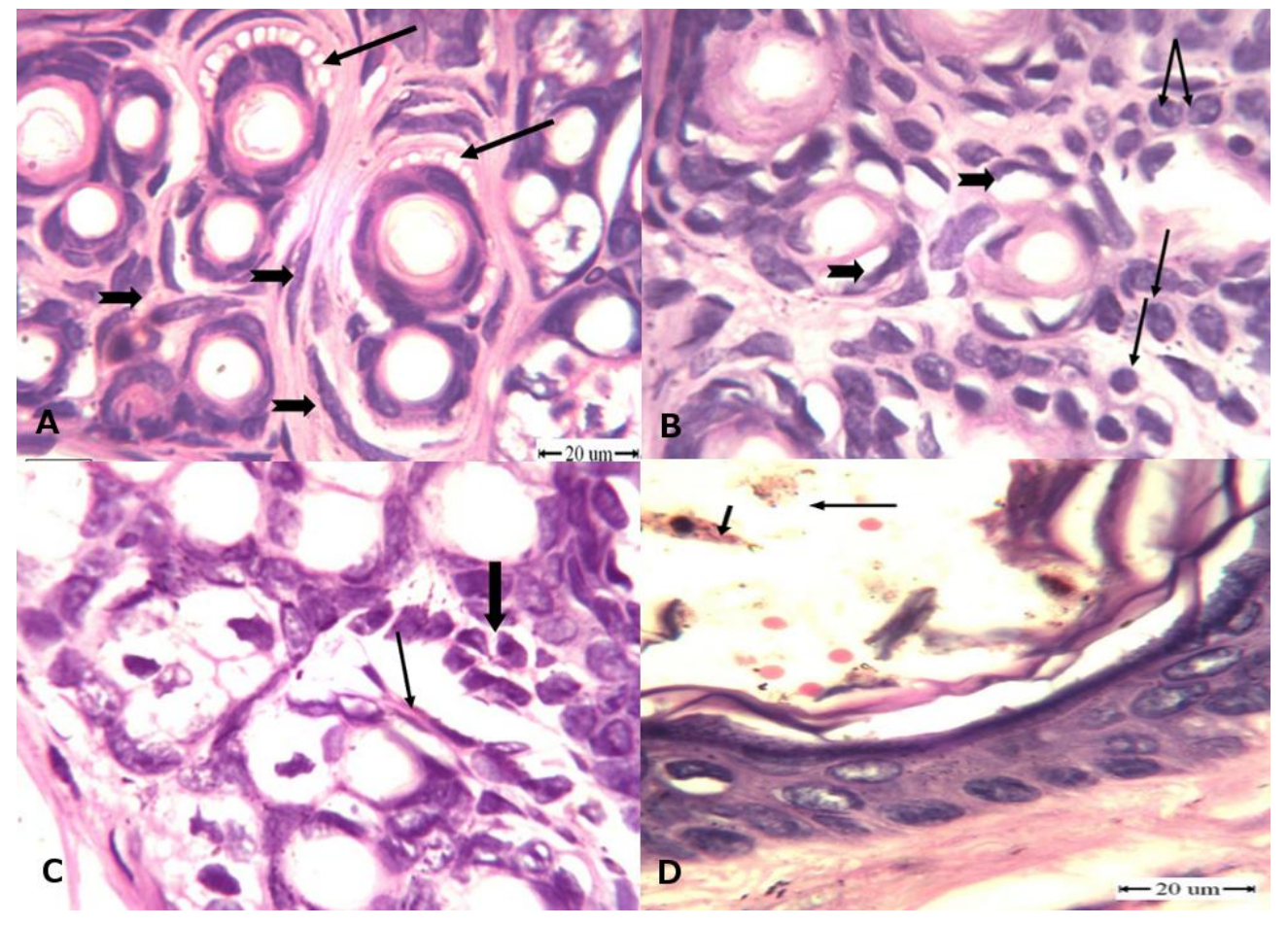

Fig. 3. (A) Hair follicles invaded by Lynxacarus egyptiacus eggs (crown-like, arrow) and surrounded by fibroblasts (arrow head). H\&E. (B) Destroyed hair follicles surrounded by fibroblasts (head arrows) and lymphocytes. H\&E. (C) Remnants of the hair shaft (arrow) surrounded by fibroblasts (head arrow) and lymphocytes. H\&E. (D) Polyplax serrata invading the keratin layer of the epidermis (arrow) with keratinolysis and minor haemorrhage. H\&E.

\section{DISCUSSION}

In the present study, well-circumscribed nodules were identified in the thigh region devoid of hairs in the Egyptian lesser blind mole rat. These nodules were either single or multiple but generally small in size (2-5mm). Moreover, skin scrapings from these areas showed flap-like external extensions of elongated Lynxacarus egyptiacus mites, which encircled the hair shaft with a clasp-like hold, as previously described (Tamam and Omar, 2009). The nodules observed in this study can be attributed to mixed infestation with both Lynxacarus egyptiacus and Polyplax serrata, in agreement with Fox et al. (2006), who observed that the Polyplax lice can cause specific lesions in mice, namely small (up to $2 \mathrm{~mm}$ ), whitish, cyst-like dermal nodules on the legs, back, trunk, abdomen, shoulders, and head. In addition, Romeiro et al. (2007) stated that infestation with Lynxacarus radovskyiin domestic cats can lead to alopecia of the dorsal and lateral areas of the hind limbs and evidence of self-mutilation with papules and crusts on the hind limbs.

In the present study, the histopathological analysis revealed a perifollicular reaction in the dermis consisting of lymphocytes and fibroblasts, together with the presence of eggs around the hair follicles or mites and eggs above the epidermis. These results suggest that Lynxacarus egyptiacus and Polyplax lice may have the ability to burrow through the epidermis or secrete toxins. Some mites that infest the skin, such as Sarcoptidae and Knemidocoptes, can tunnel into the skin and live within burrows. Others live on the skin surface (non-burrowing mites), fur, and other sites (Hoppmann and Barron, 2007; Jimenez et al., 2010; Kahn et al., 2010; Lohse et al., 2002). Nemeth et al. (2013) described lesions occurring in the white-tailed deer (Odocoileus virginianus) that microscopically consisted of epidermal crusts and cutaneous nodules with mild perifollicular lymphoplasmacytic inflammation. Gamasid mites were observed in association with L. egyptiacusand P. serrata in the present study, and were 
attached to the epidermis and resulted in destruction of keratin layer but with no significance histopathological changes.

In conclusion, mixed heavy infestations of the lesser blind mole rat with L. egyptiacus and P. serrata results in a perifollicular reaction in the dermis consisting of lymphocytes and fibroblasts with the presence of eggs around the hair follicles or mites and eggs above the epidermis.

\section{ACKNOWLEDGEMENTS}

The author gratefully acknowledges editorial assistance from Next genediting (www.nextgenediting.com).

\section{REFERENCES}

1. Fox J, Barthold S, Davisson M, Newcomer C, Quimby F and Smith A (2006). The Mouse in Biomedical Research. $2^{\text {nd }}$ edn, Elsevier Academic Press, San Diego, CA. Volume 2 - Diseases, Chapter 23 - Arthropods, p. 565-579.

2. Guo XG(1999). Cluster of ectoparasitic gamasid mites and their small mammal hosts in different habitat regions in western Yunnan. Systematic and Applied Acarology 4: 39-48.

3. Guo XG and Qian TJ (2001). Sex ratio and age structure of gamasid mites from small mammals in western Yunnan, China. Acta Entomologica Sinica 8(2): 166-174.

4. Hamid ME, Alla KM, Ahmed SS, El Shiekh AE and Ibrahim KE (2006). Unusual manifestation of a concurrent demodectic and sarcoptic mange in a Zebu-Friesian cross-bred heifer. Journal of the South African Veterinary Association 77(2): 90-91.

5. Hoppmann E and Wilson Barron H (2007). Rodent dermatology. Journal of Exotic Pet Medicine 16(4): 238-255.

6. Jimenez MD, Bangs EE, Sime C and Asher VJ (2010). Sarcoptic mange found in wolves in the Rocky Mountains in western United States. Journal of wildlife diseases 46(4): 1120-1125.

7. Kahn CM, Line S and Aiello SE (2010). The Merck Veterinary Manual. $10^{\text {th }}$ edn, Whitehouse Station, NJ: Merck and Co. Mange, p. 834-842.

8. Lohse J, Rinder H, Gothe R and Zahler M (2002). Validity of species status of the parasitic mite Otodectes cynotis. Medical and Veterinary Entomology 16: 133-138.

9. Mounsey KE, Holt DC, McCarthy JS, Currie BJ and Walton SF (2009). Longitudinal evidence of increasing in vitro tolerance of scabies mites to ivermectin in scabies-endemic communities. Archives of Dermatology 145(7): 840-841.

10. Nelson WA, Bell JF and Stewart SJ (1979). Polyplax serrate cutaneous cytologic reactions in mice that do (CFW strain) and do not (C57BL) develop resistance. Experimental Parasitology 48: 259- 264.

11. Nemeth NM, Ruder MG, Gerhold RW, Munk BA, Oester PT, Kubiski SV and Keell MK (2013). Demodectic Mange, Dermatophilosis, and Other Parasitic and Bacterial Dermatologic Diseases in Free-Ranging White-tailed Deer (Odocoileus virginianus) in the United States From 1975 to 2012. Veterinary Pathology [Epub ahead of print].

12. Philips JR (2000). A review and checklist of the parasitic mites (Acarina) of the Falconiformes and Strigiformes. Journal of Raptor Research 34(3): 210-231.

13. Romeiro ET, Alves LC, Soares YM, Matoso UN and Faustino MA (2007). Infestation by Lynxacarus radovskyi (Tenorio, 1974) in domestic cats from Metropolitan Region of Recife, Pernambuco, Brazil. Revista brasileira de parasitologia veterinaria $16(3)$ : 159-162.

14. Tamam OA and Omar HM (2009). A new record for the Lynxacarus in the Egyptian Lesser BlindMole (Spalax Leucodon Egyptiacus). European Journal of Scientific Research 33(3): 509-514.

15. Turner JC and Cano J (2008). Demodectic mange in a white-tailed deer from Walker County, Texas. Journal of Medical Entomology 45(3): 572-575. 